\title{
LAND-USE REGRESSION MODELLING OF HIGHWAY ULTRAFINE PARTICLE NUMBER CONCENTRATIONS
}

DOI \# 10.13034/CYSJ-2014-026

\author{
Scott Allan Orr \\ Southern Ontario Centre for Atmospheric Aerosol Research, Department of \\ Chemical Engineering \& Applied Chemistry, University of Toronto
}

Ultrafine particles (UFP; diameter $<100 \mathrm{~nm}$ ) are suspended atmospheric solids of concern to human health due to their small diameters. Vehicles emit significant numbers of UFP, leading to steep spatial gradients on, and near, high traffic roadways. Particle number concentrations were measured while driving a cyclic route on four Toronto highways during non-rush hour weekday periods during the summer. These data were averaged over roadway length segments to create a concentration map of the route. Road segment-averaged concentrations were bimodal, and ranged from 26,000 to 106,500 particles $\mathrm{cm}^{-3}$, which is significantly greater than the average background downtown Toronto concentration $\left(15,500 \mathrm{~cm}^{-3}\right)$. A land-use regression model incorporating diesel truck traffic, six land use types, and distance to Lake Ontario, accounted for $34 \%$ of the variability of on-road concentrations. Understanding the complex spatial distribution of urban UFP is integral to designing epidemiological studies and understanding commuter pollutant exposure.

Des particules ultrafines (PUF; diamètre < $100 \mathrm{~nm}$ ) sont des solides en suspension atmosphériques qui sont source de préoccupation pour la santé humaine en raison de leurs petits diamètres. Les véhicules motorisés émettent un grand nombre de PUF, ce qui résulte dans la formation des gradients spatiaux prononcés sur, et à proximité, des autoroutes à haute densité. Ici, des concentrations numériques des particules ont été mesurées en empruntant des routes en vélo au bord de quatre autoroutes situés à ou près de Toronto en dehors des heures de pointe en semaine pendant l'été. Une moyenne des données a été établie sur des segments de chaussée afin de créer une carte de concentration sur ces itinéraires en particulier. La moyenne des concentrations sur des segments de chaussée a été bimodale, et variait de 26,000 à 106,500 particules $\mathrm{cm}^{-3}$, ce qui est nettement supérieur à la concentration en moyenne des rues de référence situé dans le centre-ville de Toronto $\left(15,500 \mathrm{~cm}^{-3}\right)$. Un modèle de régression sur l'aménagement du territoire qui intégrait la circulation des camions à moteur diésel, six genres d'aménagement du territoire, et la distance du lac Ontario, représentaient $34 \%$ de la variabilité des concentrations sur les autoroutes. La compréhension de la distribution spatiale complexe des PUF urbaines est partie intégrante de la conception des études épidémiologiques et de la compréhension d'exposition aux polluants pour des navetteurs de banlieue.

\section{INTRODUCTION}

A irborne particulate matter (PM) has been associated with short-term health effects including increased hospitalization, medication use, and premature death, in addition to contributing to the development of cardiovascular and respiratory diseases and cancers. ${ }^{1-3}$ Ultrafine particles $\left(\mathrm{d}_{\mathrm{p}}<100 \mathrm{~nm}\right)$ are of specific concern because of the increased risks associated with their small diameters and significant number concentrations. ${ }^{4,5}$ The majority of atmospheric particles are within the ultrafine range, despite their relatively small contributions to overall PM mass; PM is currently regulated based on mass not number concentrations .

UFP concentrations are, on average, higher in urban and industrial areas due to vehicle emissions and other combustion sources. ${ }^{6}$ These concentrations vary greatly across urban areas due to dispersion near these sources and the large surface area-to-diameter ratio of UFP which promotes rapid evaporation; ${ }^{7}$ brief atmospheric residence times create steep gradients 
around roadways over relatively short distances, a characteristic distinguishes them from larger particle and many other pollutants. ${ }^{9}$ Despite this, use of wide-range spatial averages in epidemiological studies to estimate exposure rates is common. ${ }^{10-13}$

Attempts to quantify urban UFP exposure have experienced varying results. ${ }^{14-18}$ Study findings differ greatly due to unique factors such as background concentrations, vehicular regulations and emissions, and traffic frequency. Until recently, large spatial scale mapping of UFP was difficult due to the economic infeasibility of deploying monitoring instrumentation simultaneously at many sites.

As an alternate to exhaustive simultaneous measurements, land-use regression (LUR) models incorporate geographic, infrastructural, socio-economic, and meteorological factors as predictor variables for a pollutant of interest. Although these factors may not directly alter pollutant concentrations, they can serve as more easily quantifiable surrogates reflecting production or removal processes. Land-use regression has been applied to various urban air pollutants since $1997^{19}$ and has since been validated as a successful tool for predicting localized concentrations in an urban context. ${ }^{20}$

LUR has only recently been applied to UFP, and has experienced varying success (0.36 $\left.<\mathrm{R}^{2}<0.89\right){ }^{21,22,23}$ Key indicators included traffic intensity and roadway lengths, meteorological conditions, and population density indicators, which were modeled as a combination of linear and non-linear responses. Aggarwal et al. ${ }^{21}$ successfully modeled highway UFP (overall $\mathrm{R}^{2}=0.77$ ) by emphasizing local meteorological conditions, driving speed, and overall traffic volume. These studies demonstrate that landuse markers of UFP emissions are related to unique characteristics, and do not necessarily translate successfully to other regions.

This project developed a land-use regression model for central highways in Toronto, Canada, to determine what fraction of on-road variability could be explained through adjacent land-use, and evaluated whether parameters included in previous UFP LUR models contribute similarly to Toronto's roadway concentrations. It was expected that greater variability on-road would be more difficult to predict than citywide gradients, due to proximity to vehicular emissions sources.

\section{RESULTS}

Sampling conditions and data set

Fourteen repetitions of a driving route were undertaken between 11:00 and 14:00 over a two week period, June 13 and June 20, 2013. Table 1 presents the time frames and meteorological conditions for each run. Temperatures averaged $20.3 \pm 1.67^{\circ} \mathrm{C}$, while relative humidity conditions were $50 \pm 8.0 \%$ (values given as averages \pm 1 S.D.). Wind speeds were $14 \pm 5$ $\mathrm{km} / \mathrm{h}$ in predominantly NE, SE, and NW directions. Based on driving speeds of $80.8 \pm 29.4$ $\mathrm{km} / \mathrm{h}$, the runs resulted in a set of $38,469 \mathrm{ob}-$ servations, which represented approximately $99.5 \%$ of the collected data.

Table 1 Time frame and weather conditions for each run. Meteorological data provided by Environment Canada; Lester B. Pearson International Airport, $43^{\circ} 40^{\prime} 36.000^{\prime \prime} \mathrm{W}, 69^{\circ} 37^{\prime} 50.000^{\prime \prime} \mathrm{W}$. Based on 1 hour measurements; multiple hours averaged as necessary. Wind direction: $0=$ East.

${ }^{a}$ Not averaged, due to a significant shift in direction and intensity.

$\begin{array}{lllll}\text { Run } & \text { Date, time } & \text { T } & \text { RH } & \text { Wind } \\ & M M / d d, h h: m m & { }^{\circ} \mathrm{C} & \% & \mathrm{~km} / \mathrm{g}, 0 \ldots 360^{\circ} \\ 1 & 06 / 13,12: 07-12: 51 & 20.9 & 62 & 6,60 \\ 2 & 06 / 14,11: 45-12: 35 & 19.5 & 62 & 14,330 \\ 3 & 06 / 14,12: 35-13: 27 & 20.6 & 61 & 14,340 \\ 4 & 06 / 17,11: 27-12: 06 & 22.7 & 56 & 19,320 \\ 5 & 06 / 17,12: 06-12: 46 & 22.8 & 56 & 20,290 \\ 6 & 06 / 18,12: 00-12: 40 & 19.5 & 46 & 17,30 \\ 7 & 06 / 18,12: 40-13: 24 & 19.8 & 45 & 17 / 4,30 / 340^{a} \\ 8 & 06 / 18,13: 24-14: 13 & 20.0 & 49 & 4 / 14,340 / 130^{a} \\ 9 & 06 / 19,11: 24-12: 11 & 18.2 & 41 & 11,60 \\ 10 & 06 / 19,12: 11-12: 59 & 17.4 & 46 & 13,120 \\ 11 & 06 / 19,12: 59-1: 42 & 18.3 & 45 & 16,160 \\ 12 & 06 / 20,11: 57-12: 47 & 21.6 & 41 & 17,130 \\ 13 & 06 / 20,12: 47-13: 32 & 21.5 & 43 & 16,130 \\ 14 & 06 / 20,13: 32-14: 23 & 21.8 & 43 & 16,140\end{array}$




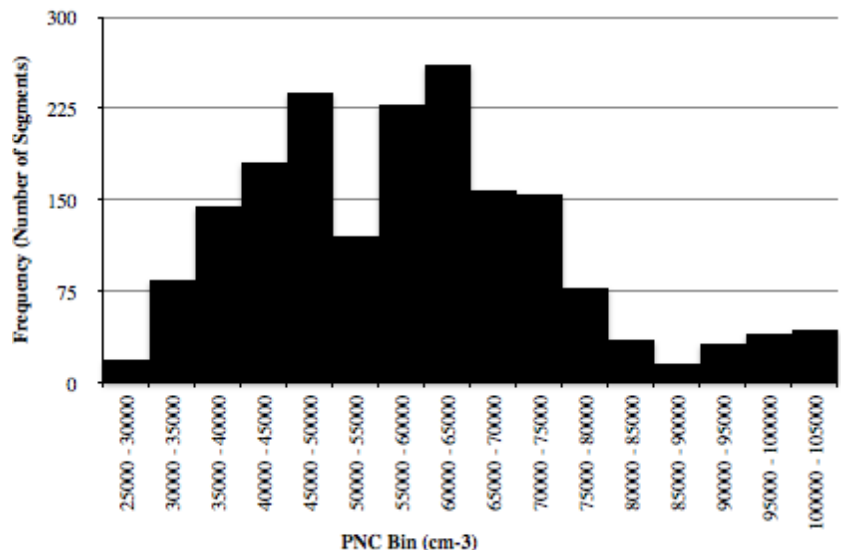

Figure 1 Highway segment-averaged concentration frequency distributions. It is unclear why the 50,000 55,000 bin (light grey) does not follow the normal trend. It is estimated that the upper range $(<90,000$, dark grey) was skewed from a normal distribution due to a few highemitting vehicles.

\section{Particle number concentrations}

The PNCs were spatially averaged over roadway segments based on pre-existing divisions created by DMTI for their provincial CanMap Route Logistics 2012 package, which are based on the unique shapes and sizes of individual lanes, exit and entrance ramps, and interchanges. The resultant averages ranged from 26,000 to 106,500 particle numbers per cubic centimetre and exhibited bimodal behaviour; see Figure 1 for a frequency distribution. See Figure 2 for a concentration map of the study's complete spatial scale. Figure 3 exhibits the high spatial resolution of the measurements taken, which enable local land-use analysis. For the sampling periods of the highway study, ambient urban UFP well away from the highway averaged $15,500 \mathrm{~cm}^{-3}$.

\section{Land-use regression model}

A land-use regression model incorporating both surrounding features and modelled vehicle traffic accounted for $34 \%$ of on-road concentration variability. A single-variable model of diesel vehicle traffic had an $\mathrm{R}^{2}=0.073$, indicating that diesel traffic alone could only explain $7.3 \%$ of the variability.

From a set of hypothesized influential urban characteristics, 22 independent variables were found that were not strongly correlated with another (Pearson $r<0.5, r>-0.5$ ). Table
2 presents the final variables included in the model and their fractional contributions to the total R2. Many permutations of this model were developed but were subsequently rejected for overfitting.

\section{Discussion}

The averaged on-road particle concentrations were much higher than the urban background $\left(57,900 \mathrm{~cm}^{-3}\right.$, compared to 15,500$)$. At a minimum, the lowest segment-averaged PNC was 26,000 $\mathrm{cm}^{-3}$, which is still significantly greater than the regional background. A relatively low correlation coefficient $\left(R^{2}=0.34\right)$, demonstrates that there are additional modelling factors needed to better understand on-road UFP gradients.

Given the limited ranges of the meteorological conditions during the sampling periods (Table 1), it is likely that these did not have a significant impact on highway concentration variability. Although previous models have had success with incorporating real-time meteorological data into LUR models, ${ }^{21}$ others have not noticed any improvement when incorporating wind roses. ${ }^{23}$ High-speed measurements made localized weather tracking difficult, which was exacerbated by sparsely-located meteorological monitoring stations in Toronto. Although, conditions experienced at Toronto's primary airport are not indicative of citywide behaviour, they are more closely related to overall urban patterns than the downtown Billy Bishop island airport, which is strongly influenced by

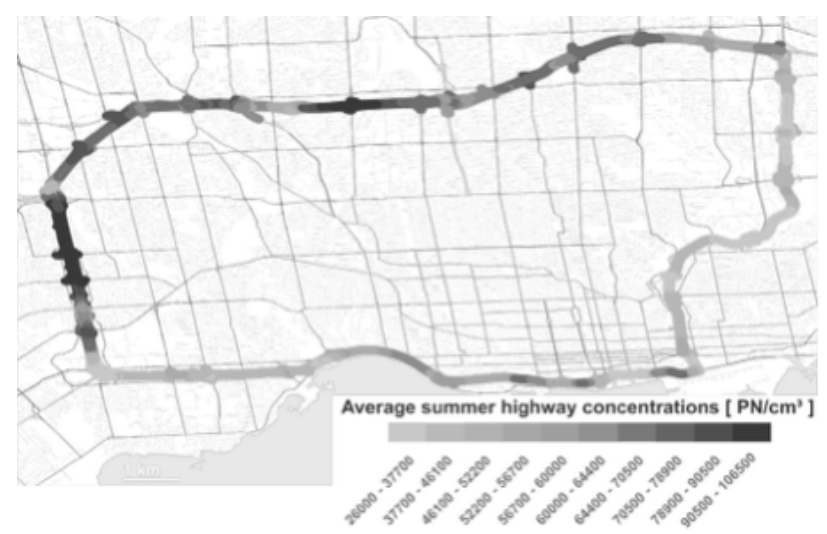

Figure 2 Concentration map based on road segment-averaged data points. The polygons have been enlarged to improve visibility at this low spatial resolution. 


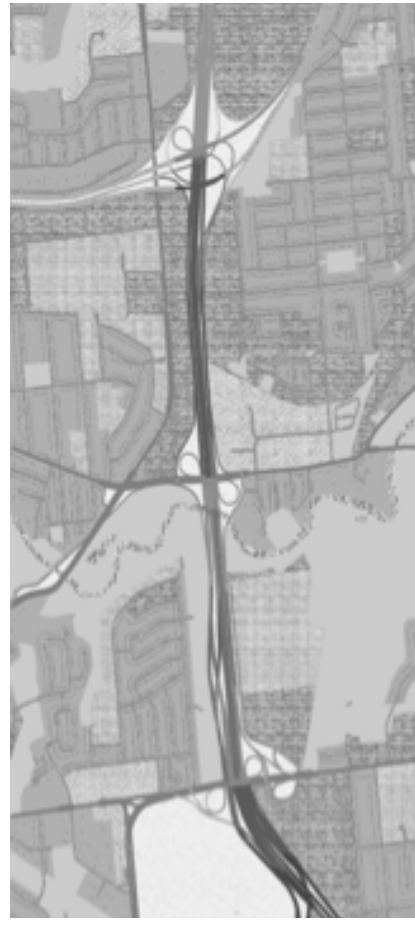

\begin{tabular}{|l|l|}
\hline Land use \\
\hline Commercial \\
Government and Institutional \\
Open Area \\
Parks and Recreational \\
\hline Residential \\
\hline Resource and Industrial \\
\hline Waterbody \\
\hline Highway \\
\hline Major road \\
\hline Local road \\
\hline Address point \\
\hline
\end{tabular}

Figure 3 Close-up of a portion of the 401 . The high spatial resolution of the measurements enable localized land-use regression.

its proximity to Lake Ontario.

Similar to the meteorological conditions, sampling times were restricted to limit the temporal dimension of variability. However, given that UFP have been shown to exhibit significant diurnal, seasonal, and long-term trends, ${ }^{24-26}$ the model developed herein has limited time-scale validity. It is expected that applying multiplicity factors based on established daily PNC trends and seasonal variation the model's temporal applicability could be expanded.

The segment-averaging method used to reduce the size of the data set smoothed over many distinct particle number events that may have improved correlation with vehicle traffic. Although this technique did sufficiently reduce the number of observations for the rigorous and time-consuming spatial algorithms, future work could be improved by random sampling and division: these provide appropriately-sized sets while not removing characteristic features of the collected measurements and allowing for cross-validation techniques. Separating the data by run also allows proper handling of sampling days suspected of nucleation events, which are wide-range events that cause significant increases in PNCs.

In addition to traffic counts, the most important variables in the developed model were land use areas and lengths of roadway. It was proposed that the density of address points might be more indicative of anthropogenic activities; address points are postal addresses marked by their GPS coordinates. However, they accounted for less than $6 \%$ of the total $\mathrm{R}^{2}$ in the final model. The model may be improved by mimicking the non-linear behavior of urban UFP with non-linear modelling, similar to work performed by Hoek et al. ${ }^{22}$ As expected, modelling of highway concentrations was less successful than the majority of studies that had a larger spatial scope $\left(\mathrm{R}^{2}=\right.$ $0.48,{ }^{23} 0.51,{ }^{27} 0.67^{22}$ ).

The model developed by Aggarwal et al. ${ }^{21}$ had a higher rate of success than the model described here-in: this is most likely due to their emphasis on local meteorology and traffic conditions, which were not fully included in this model. However, contrary to their findings, a negligible correlation was found between vehicle driving speed and particle number concentration. Expected trends of increased particle numbers on highway portions such as interchanges and ramps are represented by other variables, including the area of major roads within a $100 \mathrm{~m}$ radius.

\begin{tabular}{lll} 
Variable, radius (if applicable) & Coefficient & $\% \mathbf{R}^{2}$ \\
\hline Government and institutional area, & 0.227 & 30.9 \\
$300 \mathrm{~m}$ & & \\
Parks and Recreational, $400 \mathrm{~m}$ & -0.0747 & 28.2 \\
Length of major road, $1000 \mathrm{~m}$ & -0.108 & 16.0 \\
Diesel truck traffic, $3000 \mathrm{~m}$ & 0.0157 & 13.8 \\
Surface area of major roads, & 0.543 & 8.68 \\
$100 \mathrm{~m}$ & & \\
Residential area, $200 \mathrm{~m}$ & 0.115 & 7.06 \\
Commercial area, $200 \mathrm{~m}$ & 0.215 & 5.68 \\
Educational address points, & -3720 & 4.06 \\
$300 \mathrm{~m}$ & & \\
Distance to Lake Ontario & -0.3250 & 2.71 \\
Health address points, $500 \mathrm{~m}$ & -1630 & 1.12 \\
Intercept & 60974 & -
\end{tabular}

Table 2 The final LUR model with coefficients and percent contribution to the $R 2$. Distances and areas given in $m$ and $m 2$, respectively. Overall $R 2=0.34$. 


\section{FUTURE DIRECTIONS}

The low correlation of the developed model indicates that key Toronto-specific parameters have not been incorporated. Future efforts should explore additional literature-sourced and innovative vehicle and traffic markers while simultaneously evaluating non-linear modelling techniques, or expand the spatial scope to include non-roadway region characterized by more gradual concentration gradients.

It is hypothesized that on-road LUR may be more successfully applied to major and local roadways, which experience less longrange transport; it is predicted that the vehicle traffic on these roads is more directly related to adjacent geo-political features than their highway counterparts.

Future LUR model development of urban UFP will benefit from increased financial accessibility to accurate instrumentation, which will enable larger and more-representative basis measurements that provide the opportunity for cross-validation techniques.

Improving land-use regression models is an important component of urban source appointment of atmospheric pollutants, which contributes to the design of efficient epidemiological studies and furthers understanding of everyday commuter exposure rates.

\section{MATERIALS AND METHODS}

Instrumentation and set-up

Particle number concentrations were measured using a condensation particle counter (CPC; TSI 3007, TSI, St. Paul, MN, USA), an ultrafine particle counter (PTRAK; TSI 8525), and a handheld diffusion size classifier (DiSCmini, matter aerosol, Wohlen, Switzerland). The instruments were secured to the back seat of a passenger vehicle, and collected samples at 1 $\mathrm{Hz}$ of interior vehicle air homogenously-mixed with exterior air by driving with the vehicle's windows lowered. Each measurement was geocoded using a GPS-enabled device (GlobalSat DG-200, New Taipei City, Taiwan).

All instruments were calibrated against a pre-corrected ${ }^{28}$ Fast Mobility Particle Sizer (FMPS; TSI 3091), and the CPC's exponential over-counting of particles $>100,000 \mathrm{~cm}^{-3}$

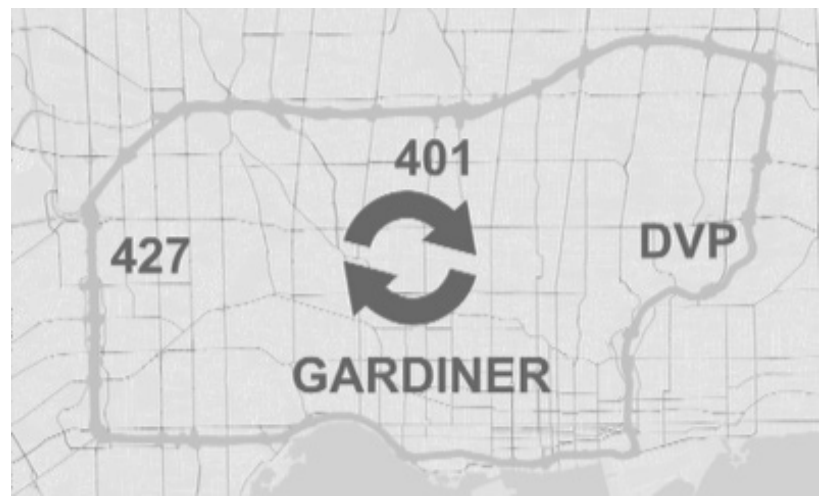

Figure 4 The spatial scope of the highway study, direction of travel indicated. The driving route incorporated Highway 427, the Gardiner Expressway (Gardiner), the Don Valley Parkway (DVP, and a portion of Highway 401.

was corrected using a method established by Westerdahl et al. ${ }^{29}$ The CPC was taken as the principle particle counter because it was the most correlated with the FMPS; missing CPC data was supplemented by the well-correlated P-TRAK, scaled to accommodate its narrower particle diameter detection range. The DiSCmini exhibited extreme over-counting and variability during the on-road campaign, and was not considered in the final results.

\section{Sampling route}

14 repetitions of the driving route were undertaken between June 13 and June 20, 2013, between 11:00 and 14:00. The highway portions included form a closed loop around the urban core of the Greater Toronto Area (Figure 4).

\section{Determining urban background UFP}

1-minute average continuous measurements of UFP were taken at a road-side downtown site (Southern Ontario Centre for Atmospheric Aerosol Research) simultaneous to the on-road campaign. Local peaks were removed from the road-site data, leaving only a signal representative of the urban background concentration (Wavelet Toolbox; MATLAB, R2012a, MathWorks).

Visualization and LUR model development Map production and spatial analysis was performed with ArcMap (ArcGIS 10.1, ESRI). To reduce the size of the data set for calculations and visualization, a new set of concentrations 
was created via averaging concentrations within $100 \mathrm{~m}$ of each polygon $(\mathrm{n}=1912)$ included in the highway casement map Shapefile (average intersections $=205$ ). These polygons represent individual highway features such including lanes, transfers, ramps, and entrance and exist routes.

Using each polygon's centroid and concentration, a multi-linear regression model was constructed utilizing a function that progressively optimizes the quantity of set of variables included in the final model (Statistics Toolbox; MATLAB, R2012a, MathWorks).

The 137 parameters included in the original set are classified into five classes: 1 ) areas of land use, 2) lengths of roadways, 3) address points, 4) traffic conditions, and 5) distance to features. The full list of variables is presented in Table 3. The variables included in the regression model were limited by the procedure outlined by Henderson et al., ${ }^{30}$ to avoid overfitting and falsely high correlation.

ABBREVIATIONS

\begin{tabular}{|l|l|}
\hline Abbreviation & Full form \\
\hline UFP & Ultrafine particles \\
\hline PM & Particulate matter \\
\hline$d_{v}$ & Particle diameter \\
\hline LUR & Land-use regression \\
\hline PN & Particle number \\
\hline RH & Relative humidity \\
\hline DVP & Don Valley Parkway \\
\hline S.D. & Standard deviation \\
\hline CPC & Condensation particle counter \\
\hline PNC & Particle number concentration \\
\hline
\end{tabular}

\section{KEY WORDS}

Ultrafine particles; Traffic emissions; Spatial gradients; Land-use regression; Particle number concentrations
Areas of Land $\mathrm{Use}^{a}\left[\mathrm{~m}^{2}\right]$

Commercial

Government and Institutional

Open Area

Parks and Recreational

Resource and Industrial

Waterbody

Highways

Major roads

Local Roads

Length of Roadway ${ }^{a[\mathrm{~m}]}$

Highways

Major roads

Local Roads

Address Points ${ }^{b}\left[\mathrm{~m}^{-2}\right]$

Total

Industrial

Low-density residential

Health centres

Parking Lots

Educational facilities

Vacant lots

Modelled traffic ${ }^{c}$

Passenger vehicles

Diesel vehicles

Distance to features

\section{Lake Ontario}

Nearest aerodrome ${ }^{a}$

Table 3 Land-use parameters included in the original variable set. Each set included radii of 100, 200, 300, 400, 500, and $1000 \mathrm{~m}$, excluding for modelled vehicular traffic (3000 m). Data sources:

a CanMap Route Logistics Ontario 2012, DMTI; Markham, Ontario.

$b$ Geospatial Competency Centre, City of Toronto;

Toronto, Ontario.

c EMME2. 


\section{ACKNOWLEDGEMENTS}

Many thanks to Kelly Sabaliauskas, Ezzat Jaroudi, Tasnim American, and other members of the SOCAAR research group who supported this project's design, implementation, and analysis. A special word of appreciation to Professor Greg Evans and the Department of Chemical Engineering and Applied Chemistry, University of Toronto, for giving me the opportunity to develop my research and communication skills through this project.

This work was undertaken with the support of Health Canada.

\section{REFERENCES}

1. Dockery, D. W.; Pope, C. A.; Xu, X.; Spengler, J. D.; Ware, J. H.; Fay, M. E.; Ferris, B. G.; Speizer, F. E. An Association between Air Pollution and Mortality in Six U.S. Cities. New. Engl. J. Med. 1993, 329, 1753-1759. DOI: 10.1056/ NEJM199312093292401

2. Dockery, D. W. Epidemiologic Evidence of Cardiovascular Effects of Particulate Air Pollution. Environ. Health. Persp. 2001, 109, 483-386. DOI: $10.2307 / 3454657$

3. Pope, C. A. III; Burnett, R. T.; Thun, M. J.; Calle, E. E.; Krewski, D.; Ito, K.; Thurston, G. D. Lung Cancer, Cardiopulmonary Mortality, and Long-term Exposure to Fine Particulate Air Pollution. J. Am. Med. Assoc. 2002, 287, 1132-1141.

DOI: $10.1001 /$ jama.287.9.1132

4. Ibald-Mulli, A.; Wichmann, H.-E.; Kreyling, W.; Peters, A. Epidemiological Evidence on Health Effects of Ultrafine Particles. J. Aerosol Med. 2002, 15, 189-201, DOI: $10.1089 / 089426802320282310$

5. Donaldson, K; Li, X.; MacNee, W. Ultrafine (nanometre) particle mediated lung injury. J. Aerosol Sci. 1998, 29, 553-560. DOI: $10.1016 /$ S0021-8502(97)00464-3

6. Seigneur, C. Current Understanding of Ultrafine Particulate Matter Emitted from Mobile Sources. J. Air Waste Manage. 2009, 59, 3-17. DOI: 10.3155/1047-3289.59.1.3

7. Kittelson, D. B. Engines and nanoparticles: a review. J. Aerosol Sci. 1998, 29, 575-588. DOI:
10.1016/S0021-8502(97)10037-4

8. Zhu, Y.; Hinds, W.; Kim, S.; Sioutas, C.

Concentration and Size Distribution of Ultrafine Particles Near a Major Highway. J. Air Waste Manage. 2002, 52, 1032-1042. DOI: 10.1080/10473289.2002.10470842

9. Beelen, R.; Hoek, G.; Vienneau, D.; Eeftens, M.; Dimakopoulou, K.; Pedeli, X.; Tsai, M.-Y.; Künzli, N.; Schikowski, T.; Marcon, A. et al. Development of NO2 and NOx land use regression models for estimating air pollution exposure in 36 study areas in Europe - The ESCAPE project. Atmos. Environ. 2013, 72, 10-23. DOI: 10.1016/j.atmosenv.2013.02.037 10. Jerrett, M.; Arain, A.; Kanaroglou, P.; Beckerman, B.; Potoglou, D.; Sahsuvaroglu, T.; Morrison, J.; Giovis, C. A review and evaluation of intraurban air pollution exposure models. J. Expo. Sci. Env. Epid. 2004, 185-204. DOI: 10.1038 / sj.jea.7500388

11. Pekkanen, J.; Kulmala, M. Exposure assessment of ultrafine particles in epidemiologic time-series studies. Scand. J. Work Env. Hea. 2004, 30 (S.2), 9-18.

12. Wilson, J.; Kingham, S.; Pearce, J.; Sturman, A. A review of intraurban variations in particulate air pollution: Implications for epidemiological research. Atmos. Environ. 2005, 39, 64446462. DOI: $10.1016 /$ j.atmosenv.2005.07.030 13. Morawska, L.; Ristovski, Z.; Jayaratne, R.; Keogh, D. U.; Ling, X. Ambient nano and ultrafine particles from motor vehicle emission: Characteristics, ambient processing and implcations on human exposure. Atmos. Environ. 2008, 42, 8113-8138. DOI: 10.1016/j. atmosenv.2008.07.050

14. Barone, T. L.; Zhu, Y. The morphology of ultrafine particles on and near major freeways. Atmos. Environ. 2008, 42, 6749-6758. DOI: 10.1016/j.atmosenv.2008.05.019

15. Buonanno, G.; Lall, A.; Stabile, L. Air Pollution Related to Transport. Atmos. Environ. 2009, 43, 1100-1105. DOI: 10.1016/j.atmosenv.2008.11.011 16. Diapouli, E.; Grivas, G.; Chaloulakou, A.; Spyrellis, N. PM10 and Ultrafine Particl Counts In-Vehicle and On-Road in the Athens Area. Water, Air, E Soil Pollution: Focus 2008, 8, 89-97. DOI: $10.1007 /$ s11267-007-9136-8 
17. Klems, J. P.; Pennington, M. R.; Zordan, C. A.; Johnston, M. V. Ultrafine Particles Near a Roadway Intersection: Origin and Apportionment of Fast Changes in Concentration. Environ. Sci. Technol. 2010, 44, 7903-7907. DOI: 10.1021/es102009e

18. Zhu, Y.; Hinds, W. C.; Shen, S.; Sioutas, C. Seasonal Trends of Concentration and Size Distribution of Ultrafine Particles Near Major Highways in Los Angeles. Aerosol Sci. Tech. 2004, 38 (S.1), 5-13. DOI: $10.1080 / 02786820390229156$ 19. Briggs, D.; Collins, S.; Elliott, P.; Fischer, P.; Kingham, S.; Lebret, E.; Pryl, K.; Van Reeuwijk, H.; Smallbone, K.; Van Der Veen, A. Mapping urban air pollution using GIS: a regressionbased approach. Int. J. Geogr. Inf. Sci. 1997, 11, 699-718.

20. Ryan, P.; Lemasters, G. A Review of Land-use Regression Models for Characterizing Intraurban Air Pollution Exposure. Inhal. Toxicol. 2007, 19, 127-133. DOI: $10.1080 / 08958370701495998$

21. Aggarwal, S.; Jain, R.; Marshall, J. Real-Time Prediction of Size-Resolved Ultrafine Particulate Matter on Freeways. Environ. Sci. Technol. 2012, 46, 2234-2241. DOI: 10.1021/es203290p 22. Hoek, G.; Beelen, R.; Kos, G.; Dijkema, M.; Zee, S.; Fischer, P.; Brunekreef, B. Land Use Regression Model for Ultrafine Particles in Amsterdam. Environ. Sci. Technol. 2011, 45, 622-628. DOI: 10.1021 / es1023042

23. Abernethy, R.; Allen, R.; McKendry, I.; Brauer, M. A Land Use Regression Model for Ultrafine Particles in Vancouver, Canada. Environ. Sci. Technol. 2013, 47, 5217-5225. DOI: 10.1021 / es304495s

24. Sabaliauskas, K.; Jeong, C.-H.; Yao, X.; Jun, Y.-S.; Jadidian, P.; Evans, G. J. Five-year roadside measurements of ultrafine particles in a major Canadian city. Atmos. Environ. 2012, 49, 245-256. DOI: 10.1016/j.atmosenv.2011.11.052 25. Zhang, K.; Wexler, A.; Zhu, Y.; Hinds, W.; Sioutas, C. Evolution of particle number distribution near roadways. Part II: the 'Road-to-Ambient' process. Atmos. Environ. 2004, 38, 6655-6665. DOI: 10.1016/j.atmosenv.2004.06.044

26. Fine, P.; Chakrabarti, B.; Krudysz, M.;
Schauer, J.; Sioutas, C. Diurnal Variations of Individual Organic Compound Constituents of Ultrafine and Accumulation Mode Particulate Matter in the Los Angeles Basin. Environ. Sci. Technol. 2004, 38, 1296-1304. DOI: 10.1021/ es0348389

27. Rivera, M.; Basagaña, X.; Aguilera, I.; Agis, D.; Bouso, L.; Foraster, M.; Medina-Ramón, M.; Pey, J.; Künzli, N.; Hoek, G. Spatial distribution of ultrafine particles in urban settings: A land use regression model. Atmos. Environ. 2012, 54, 657-666. DOI: 10.1016/j.atmosenv.2012.01.058 28. Jeong, C.-H.; Evans, G. J. Inter-Comparison of a Fast Mobility Particle Sizer and a Scanning Mobility Particle Sizer Incorporating an Ultrafine Water-Based Condensation Particle Counter. Aerosol Sci. Tech. 2009, 43, 364-373. DOI: $10.1080 / 02786820802662939$ 29. Westerdahl, D.; Fruin, S.; Sax, T.; Fine, P.; Sioutas, C. Mobile platform measurements of ultrafine particles and associated pollutant concentrations on freeways and residential streets in Los Angeles. Atmos. Environ. 2005, 39, 35973610. DOI: 10.1016/j.atmosenv.2005.02.034 30. Henderson, S. B.; Beckerman, B.; Jerrett, M.; Brauer, M. Application of Land Use Regression to Estimate Long-Term Concentrations of Traffic-Related Nitrogen Oxides and Fine Particulate Matter. Environ. Sci. Technol. 2007, 41, 2422-2428. DOI: 10.1021 / es0606780 


\section{REVIEW OF: "LAND-USE REGRESSION MODELLING OF HIGHWAY ULTRAFINE PARTICLE NUMBER CONCENTRATIONS"}

Reviewed by: Prof. Greg Evans

Director, Southern Ontario Centre for

Atmospheric Aerosol Research

Department of Chemical Engineering \&

Applied Chemistry

University of Toronto

Ultrafine particle exposure assessment is a new and rapidly evolving area of research. Despite two decades of scientific interest, only a few urban areas have continuous long-term ( $>5$ years) ultrafine concentration data with even fewer having quantified concentration spatial gradients. Mapping ultrafine particles across an urban area is ambitious due to its multiple sources, transformation processes and elimination pathways. Exiting studies that attempt to characterize ultrafine particle concentration spatial gradients have utilized a central urban monitoring site, or a combination of a few sites, as a representation of citywide behavior. However, ultrafine particles exhibit steep concentration gradients around roadways and monitoring ultrafine particles at only a few locations does not necessarily capture this variability. Mobile monitoring is challenging because ultrafine particles exhibit temporal variability due to the movement of vehicles throughout the city and changes in meteorology. Traffic patterns in most cities exhibit a daily trend that includes a morning and afternoon rush period. This macro-scale change in vehicle number across the city can impact the observed concentration of ultrafine particles. Further, local temperature and wind fluctuations affect the growth and transport of ultrafine particles, which are difficult to incorporate into mobile monitoring.

On-road monitoring may provide complimentary information about ultrafine particles in urban areas; for example, this study collected ultrafine particle measurements at more locations than previously published and benefits from repeated measurements. This work demonstrates that relationships between repeated mobile measurements and land-use near highways can be established. This approach may be useful for future studies that will seek to balance the competing needs to capture both spatial and temporal variation of ultrafine particles to assess urban population exposure. 